\title{
Enterprise profiles in deprived areas: are they distinctive?
}

\author{
Julian S. Frankish*, Richard G. Roberts and \\ David J. Storey
}

Barclays Bank PLC

Barclays House, 1 Wimborne Road

Poole BH15 2BB, UK

E-mail: julian.frankish@barclays.com

E-mail: richard.roberts@barclays.com

E-mail: david.storey@wbs.ac.uk

*Corresponding author

\begin{abstract}
This paper examines the extent to which segmenting business activity on the basis of the relative deprivation of a given area provides additional understanding (in terms of analysis and policy) that is not obtained by alternative divisions, e.g., by sector, size, etc. The paper is primarily motivated by the explicit inclusion of a deprived area dimension to many UK small business/enterprise policies introduced since 1997. We use two datasets drawn from the customer records of Barclays Bank PLC to obtain an initial analysis of the business stocks and dynamics in deprived and non-deprived areas of England. The data indicate that the deprived areas of England vary systematically from the wider economy in terms of several business stock characteristics and associated dynamics. These differences include a lower proportion of business service firms, lower female involvement in the owner-manager base and a poorer risk profile. The analysis supports the view that there are likely to be benefits from the tailoring of small business/ enterprise policies to sub-national levels.
\end{abstract}

Keywords: deprived areas; business; start-up; public policy.

Reference to this paper should be made as follows: Frankish, J.S., Roberts, R.G. and Storey, D.J. (2010) 'Enterprise profiles in deprived areas: are they distinctive?', Int. J. Entrepreneurship and Small Business, Vol. 9, No. 2, pp.127-142.

Biographical notes: Julian S. Frankish is a Senior Economist at the SME Market Analysis Team of Barclays Bank PLC. Richard G. Roberts is the SME Market Analysis Director for Barclays Bank PLC and heads the SME Market Analysis Team. Between them, they have many years of experience in researching and analysing the UK small business market, primarily from a commercial perspective, but also with close links to public policy and academic research in this area.

David J. Storey is Professor at Warwick Business School. His research interests cover small business and enterprise, with a particular interest in public policy in this area and its evaluation. 


\section{Introduction}

The primary focus of this paper is on business activity in 'deprived areas'. Small business and enterprise policy in the UK has and continues to be concerned with new and established businesses. Our interest is in examining to what extent a division of business activity into deprived and non-deprived areas provides a useful segmentation of the business stock with respect to policy goals.

This paper presents only an initial analysis of these issues, with the intention of examining them in more detail in future work. However, even this basic assessment of the available data indicates that there are significant differences between deprived and non-deprived areas with respect to the profile of their business stocks and the dynamics of their new firms. More importantly, the data indicate that these differences are not a result of the interaction of the geographic distribution of deprived areas and regional variations in business activity.

The remainder of the paper is set out as follows. Section 2 provides a brief overview of the interest in and policy towards business/enterprise in deprived areas. Section 3 summarises the definition of deprived areas used in this paper. Section 4 sets out the data used in our initial analysis. Section 5 presents an overview of the business stocks and considers in more detail three aspects of the data we judge to be of particular policy interest - sector composition, female involvement and risk. Section 6 moves on to consider the dynamics of business activity. Section 7 draws the paper together and sets out the direction of future work suggested by our initial analysis.

\section{Context}

There has been a policy interest in business activity in deprived areas of the UK stretching back to before the Second World War. Policies put in place to support areas suffering as a result of the Great Depression of the early 1930s served as the forerunners of a more structured and comprehensive framework of regional (and local) planning and assistance after 1945. However, policies such as Regional Selective Assistance supported an objective of full employment rather than any concept of developing small firms. The main aim was to encourage business activity by large firms (including state-owned ones) to remain or relocate to certain areas.

Even with the discovery of small business policy as a distinct issue in the late 1960s, UK government interest in deprived areas remained primarily in either addressing economic dislocation and resulting unemployment or controlling success (such as office development permits in the South East in the 1970s construction boom). The initial policies of the 1979 Conservative government continued in this vein as the 1980-1981 recession again placed the focus on immediate support for areas affected by the loss of manufacturing employment through measures such as the creation of Enterprise Zones. ${ }^{1}$ Even the controversial Enterprise Allowance Scheme can be seen in the same light of the overwhelming question of unemployment. The fact that one of the first small business policies with an explicit deprived area dimension - a short-lived modification of the Small Firms Loan Guarantee Scheme in the early-1990s to provide an inner-city version - is perhaps testament to the limited tailoring of national enterprise policies to these localities. 
In the 1990s the easing of concerns over unemployment resulted in a greater interest in other aspects of economic performance, particularly productivity. In turn, this produced a focus on below average areas. At the same time those closely associated with the reinvention of the Labour Party saw enterprise as a vital component in meeting their objectives for the regeneration of deprived areas and tackling wider social exclusion. They argued that these areas were not less entrepreneurial, but rather lacked the resources to put enterprise into practice (Gavron et al., 1998; Westall et al., 2000).

From 1997 government ministers took up the theme of enterprise as a means to address wider problems. This culminated with the publication of Enterprise and Social Exclusion (HM Treasury, 1999) which stated in its overview that: "The goal of this report is to identify how to generate more enterprise in deprived communities" (p.1). Since this point there have been a range of policies that, in contrast to the periods discussed above, seek to link enterprise and deprived areas. These include the creation of Enterprise Areas, the introduction of the Community Investment Tax Credit and additional funding to business advice and support, first through the Phoenix Fund and then after 2006 via the Local Enterprise Growth Initiative. In addition, there has been support for initiatives, including the Inner City 100 survey and Enterprise Britain, which have sought to change perceptions rather than fund projects.

The clear implication of all of these policies is that deprived areas face issues relating to enterprise that are distinct from a simple difference in the composition of the business stock. That is, there is value to be obtained from dividing businesses and enterprise activity into that which does and does not occur in deprived areas, in the same way that other policies focus on the ethnic background or gender of the owner-manager(s). Our aim is to examine whether deprived areas can be considered a distinct segment of the business stock and, if so, in what ways do they differ.

\section{Defining deprived areas}

The definition of deprived areas used in this paper is based on the Index of Multiple Deprivation (IMD) for England ${ }^{2}$ (ODPM, 2004). The IMD is constructed using data on seven aspects or domains of deprivation - income, employment, health, education, housing, environment and crime. An IMD score, based on these domains, is available for each of the c.32 000 (lower layer) Super Output Areas ${ }^{3}$ (SOAs) in England.

The data used in this paper (see next section) are defined using postcode geography rather than SOAs. Therefore, the headline IMD has been converted to fit the c.8000 post sectors in England using the National Statistics Postcode Database (NSPD) for August 2006. The IMD score for each sector is the mean score for the underlying postcodes of that sector.

The resulting IMD-equivalent ranking of post sectors leaves the question of a suitable definition for a deprived area. The IMD provides a continuum of deprivation rather than a clear dividing line. For the purpose of this paper we decided to select the most deprived $10 \%$ of sectors derived from the conversion outlined above, 809 in total.

There are two aspects to the geographic distribution of deprived sectors that are of particular note. First, they are predominantly located in the north of England, with 70\% found in the North West, North East and Yorkshire (see Figure 1a). As a result deprived areas account for a high proportion of the sectors in these regions. Second, they are 
overwhelmingly located in urban areas. $95 \%$ of deprived sectors have $98 \%$ or more of their constituent postcodes classified as urban, ${ }^{4}$ while the same is true for only $55 \%$ of non-deprived sectors (Figure 1b). This distribution indicates the importance of choosing a suitable base for comparative analysis. Therefore, the analysis presented in this paper is restricted to only those firms located in overwhelmingly urban sectors, whether deprived or not. ${ }^{5}$

Figure 1a Deprived areas in England (see online version for colours)

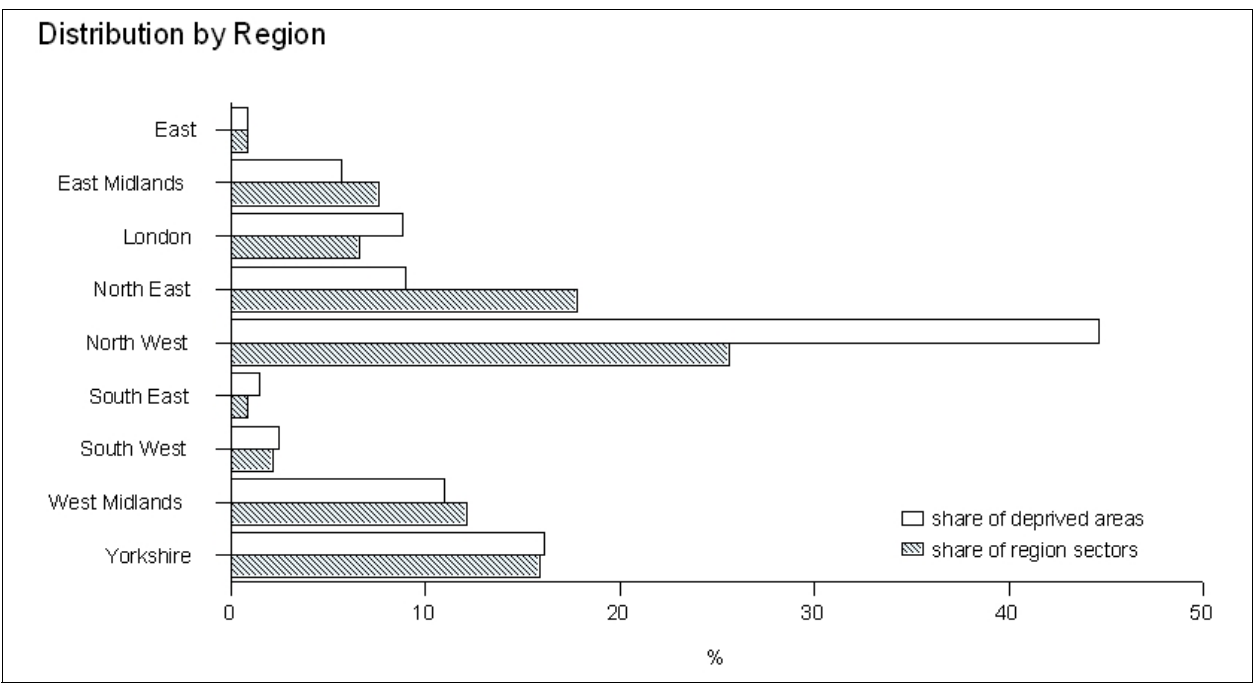

Source: ONS (2007); Barclays (2007)

Figure 1b Deprived urban areas in England (see online version for colours)

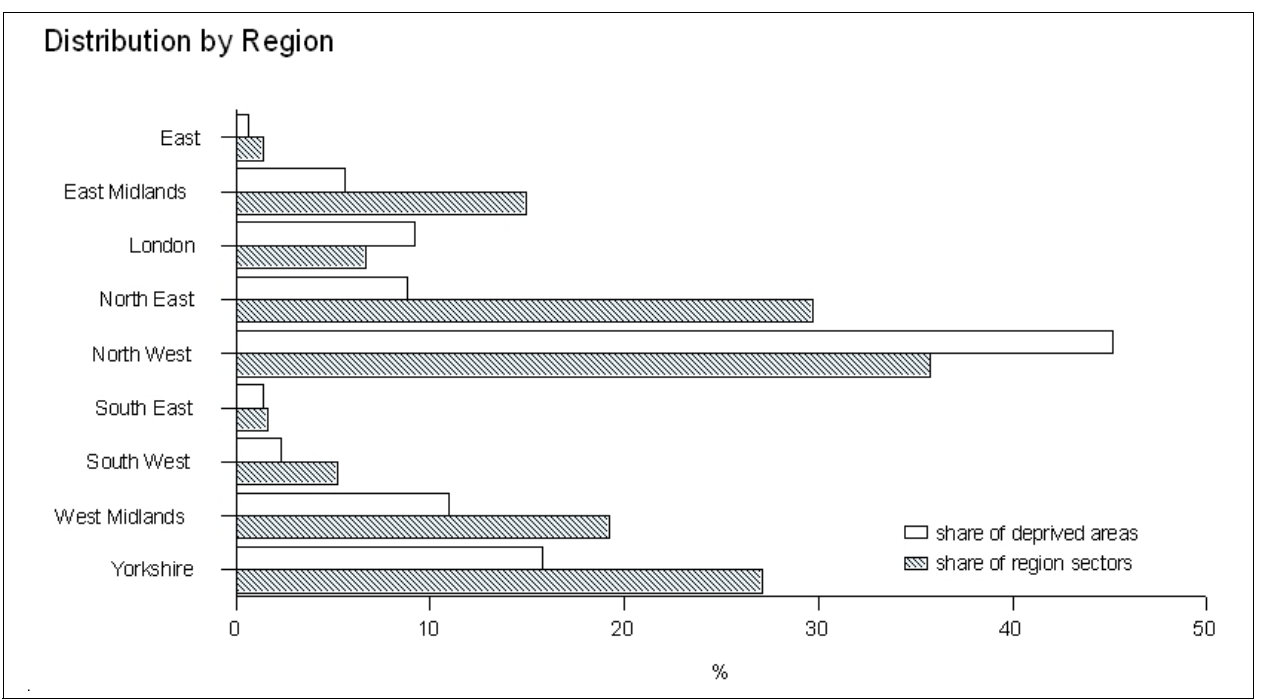

Source: ONS (2007); Barclays (2007) 


\section{Data}

A key feature of this paper is the use of customer records from Barclays Bank PLC, one of the main UK providers of banking services to small firms, to review business demographics at a local level. This is the first time this has been done on such a scale in the UK. ${ }^{6}$ The use of bank data in this way has often been suggested as a potentially vital untapped source of information to aid research and policy development (Thomas et al., 2006). This analysis offers an initial test of this assertion.

Bank data are in many ways very detailed and timely. The absence of a comprehensive business database in the UK means that bank customers are more representative of the business stock than those firms present on official registers. There are more than 3 million businesses operating using a business current account in the UK (BBA, 2007). In comparison, there are only 1.7 million (active) firms registered for Value Added Tax (ONS, 2007), with a further 0.4 million on the Interdepartmental Business Register (BERR, 2007) that includes those subject to the Pay As You Earn system of tax collection for employees.

However, it should be recognised that the use of bank data as a basis for research also has its disadvantages. In particular, the records themselves and the databases compiled have never been designed with a research function in mind. Collecting and aggregating data across a number of institutions presents particular difficulties, as definitions will vary, even for something as apparently straightforward as defining what constitutes a customer. The use of proprietary software compounds a number of these problems and makes access to the data by a third party without the direct involvement of the bank extremely unlikely. Finally, these data are not official statistics but commercially sensitive records and subject to the requirements of data protection legislation.

To date, one of the rare attempts to collect regular bank wide data in the area of small business is undertaken by the British Bankers Association (BBA, 2007). The BBA Small Firms Committee began to collect some national data on bank support for firms with turnover of less than $£ 1$ million in the early 1990s. Following a request from the Bank of England in 2000, some of the data have been collated at a sub-national level in order to look at bank activity in deprived areas. ${ }^{7}$ Also, following requests from the UK House of Commons Treasury Select Committee, some individual banks have disclosed their own activities (Co-op, 2006; Barclays, 2007). However, this discussion paper uses a more detailed extract of bank data than has previously been made available in the public domain.

Looking in more detail at the bank records used in this paper, two datasets were used in the analysis.

The first is a large sample of the business stock drawn from the business customer records of Barclays Bank as at end-March 2007. The dataset includes 221000 (non-financial) firms, more than $5 \%$ of all businesses in England as at the last official estimate (SBS, 2006). The available variables cover a number of key business characteristics, including turnover, sector and age, as well as information on default risk and limited additional data on owner-managers. The large size of the dataset means that it is possible to provide robust comparative analysis of the business stock down to quite small geographic levels. Table 1 sets out the available data in more detail. 
Table 1 Business stock data: selected variables

\begin{tabular}{|c|c|}
\hline Variable & Description \\
\hline Turnover & $\begin{array}{l}\text { Non-zero annual debit turnover - money paid out - from all current } \\
\text { accounts associated with the business. }\end{array}$ \\
\hline Sector & $\begin{array}{l}\text { Broad business sector of the firm - agriculture, business services, } \\
\text { construction, Health, Education \& Social Work (HESW), hotels and } \\
\text { catering, manufacturing, motor trades, other services, property services, } \\
\text { retail and transport. }\end{array}$ \\
\hline Legal form & Company, Limited Liability Partnership (LLP), partnership or sole trader \\
\hline Business age & $\begin{array}{l}\text { The age of the business based on the date of the first account opened } \\
\text { with Barclays. }\end{array}$ \\
\hline Owner age & $\begin{array}{l}\text { Age of individual identified as 'owner of...', 'director of...' or 'partner } \\
\text { of...' the business. Mean age when there are two or more individuals. }\end{array}$ \\
\hline Female involve & Any of the individual(s) associated with the business are female. \\
\hline OD limit & Business has a non-zero overdraft limit. \\
\hline Term loan & Business has a term loan (including commercial mortgage). \\
\hline Education & $\begin{array}{l}\text { Highest educational attainment of individual(s) associated with the } \\
\text { business - none, basic school qualifications (nvq2), advanced school } \\
\text { qualifications (nvq3), graduate/post-graduate qualifications (nvq4). } \\
\text { Drawn from voluntary questions. }\end{array}$ \\
\hline Business experience & $\begin{array}{l}\text { Previous business experience of owner-manager(s) - none, family, self, } \\
\text { self \& family. Drawn from voluntary questions. }\end{array}$ \\
\hline Advice/Support & $\begin{array}{l}\text { Sources of advice/support prior to start-up - enterprise agency/ } \\
\text { business link, accountant, solicitor, family/friends, other. Drawn from } \\
\text { voluntary questions. }\end{array}$ \\
\hline PD_pctile & $\begin{array}{l}\text { Percentile position of the business in Barclays probability of default } \\
\text { distribution. The total distribution (in this instance) is based on } 384000 \\
\text { firms in England. }\end{array}$ \\
\hline IMD_pctile & $\begin{array}{l}\text { Percentile position of the post sector in which the business is based } \\
\text { relative to the English Index of Multiple Deprivation } 2004 \text {. }\end{array}$ \\
\hline
\end{tabular}

The second dataset consists of new firms opening with Barclays in England during December 2002, March 2003 and June 2003.These firms all opened a new business current account during these months and were identified as never previously having held a similar account. The 12000 firms available in this dataset provide an opportunity to analyse the dynamics of new firms in terms of both survival and growth.

\section{Analysis: stock}

In this section we present an overview of the business stock dataset outlined above. The analysis then moves on to consider in more detail three aspects of the dataset that we consider to be of particular policy interest.

Table 2 sets out the profiles of the business stocks in deprived and non-deprived areas. The dataset reveals that there are significant differences between these areas across a range of business characteristics. ${ }^{8}$ 
Table 2 Deprived and non-deprived urban areas: business profiles, selected variables (\% of firms)

\begin{tabular}{|c|c|c|c|c|c|}
\hline Variable & Deprived & Non-deprived & Variable & Deprived & Non-deprived \\
\hline Turnover & & & Female involve & & \\
\hline$<£ 10 \mathrm{k}$ & 25.1 & 24.6 & Yes & 29.6 & 32.5 \\
\hline$£ 10-25 \mathrm{k}$ & 16.1 & 16.1 & OD limit & & \\
\hline$£ 25-50 \mathrm{k}$ & 12.8 & 14.6 & Yes & 27.1 & 26.1 \\
\hline$£ 50-100 \mathrm{k}$ & 10.7 & 12.9 & Term loan & & \\
\hline$£ 100-250 \mathrm{k}$ & 12.6 & 13.0 & Yes & 9.9 & 8.1 \\
\hline$£ 250 \mathrm{k}-1 \mathrm{~m}$ & 13.9 & 12.1 & Education & & \\
\hline$£ 1 \mathrm{~m}+$ & 8.7 & 6.7 & None & 27.8 & 26.5 \\
\hline Sector & & & NVQ2 & 20.6 & 18.6 \\
\hline Agriculture & 0.4 & 0.7 & NVQ3 & 11.3 & 11.8 \\
\hline Business services & 21.8 & 28.9 & NVQ4 & 40.2 & 43.0 \\
\hline Construction & 9.4 & 13.5 & Business experience & & \\
\hline HESW & 3.0 & 3.1 & None & 24.5 & 25.7 \\
\hline Hotels and catering & 8.7 & 6.0 & Family & 11.1 & 10.4 \\
\hline Manufacturing & 9.9 & 6.4 & Self & 22.8 & 26.3 \\
\hline Motor trades & 3.9 & 2.8 & Self and family & 41.6 & 37.5 \\
\hline Other services & 11.8 & 13.7 & Advice/Support & & \\
\hline Property services & 4.6 & 5.7 & Ent agent/bus link & 7.8 & 5.6 \\
\hline Retail & 16.0 & 11.0 & Accountant & 29.5 & 30.9 \\
\hline Transport & 4.6 & 4.0 & Solicitor & 5.0 & 4.1 \\
\hline Wholesale & 6.0 & 4.0 & Family & 25.4 & 21.5 \\
\hline Legal form & & & Other & 5.6 & 5.5 \\
\hline Company & 50.6 & 54.1 & PD_pctile & & \\
\hline LLP & 0.2 & 0.2 & $1-10$ & 15.7 & 11.2 \\
\hline Partnership & 14.1 & 13.6 & $11-20$ & 12.7 & 10.7 \\
\hline Sole trader & 35.1 & 32.1 & $21-40$ & 22.5 & 21.6 \\
\hline Business age & & & $41-60$ & 18.3 & 20.5 \\
\hline under 1 & 21.7 & 18.2 & $61-80$ & 16.1 & 19.2 \\
\hline $1-3$ & 29.8 & 27.4 & $81-100$ & 14.6 & 16.8 \\
\hline $3-5$ & 14.3 & 15.3 & & & \\
\hline $5-10$ & 15.5 & 16.9 & & & \\
\hline 10 and over & 18.7 & 22.1 & & & \\
\hline \multicolumn{6}{|l|}{ Owner age } \\
\hline under 25 & 3.4 & 2.2 & & & \\
\hline $25-34$ & 21.3 & 17.3 & & & \\
\hline $35-44$ & 30.6 & 30.2 & & & \\
\hline $45-54$ & 26.1 & 27.2 & & & \\
\hline $55-64$ & 14.7 & 17.6 & & & \\
\hline 65 and over & 3.9 & 5.4 & & & \\
\hline
\end{tabular}

Notes: $\quad \mathrm{N}($ Deprived $)=21$ 289; except Education, Business experience and Advice/Support (= 5225).

$\mathrm{N}$ (Non-deprived) $=200$ 171; except Education, Business experience and Advice/Support (= 49081$)$.

Figures shown as 0.0 highlight significant differences between the deprived and non-deprived percentages of a given variable component, e.g., the proportion of companies within the variable Legal form. A Pearson chi-squared test,

significant at least at the $10 \%$ level, indicates differing profiles for that variable. In addition, the adjusted standardised residual for that variable component has an absolute value of at least two, indicating that differences in this aspect of the variable are contributing to the Pearson test result. 
The data show that deprived areas have a higher proportion of larger firms - those with a turnover of $£ 250,000$ or more - with a corresponding lower share of mid-sized firms in the $£ 25,000-£ 100,000$ turnover range. Deprived areas have a significantly lower use of incorporation, with the share of companies in the total stock more than three percentage points below that for the rest of England. The dataset also highlights the youth of businesses in deprived areas, both in terms of business and owner-manager age. More than $51 \%$ of deprived area firms had been in existence for less than three years, against less than $46 \%$ elsewhere. Similarly, nearly $25 \%$ of owner-managers were under 35 years of age, while this was the case for less than $20 \%$ of firms in non-deprived areas. Further variables indicate differences in the use of external finance and the take-up of external advice and/or support prior to start-up.

The differences mentioned above indicate that deprived areas show significant and important contrasts in business activity from the rest of the country. However, for reasons of brevity and clarity, our more detailed analysis of the dataset concentrates on three aspects of the stock - sector composition, female involvement and risk - that we consider to be of particular policy interest. The first of these reflects concern that there is not only less business/enterprise activity in deprived areas, but that what exists is disproportionately focused on less 'attractive' sectors. Female enterprise was included as an explicit target of the government's 2004 action plan for small business (SBS, 2004) and this has been followed up by the creation of a Women's Enterprise Task Force in 2007. Finally, the risk profile of businesses is closely linked to the availability of external finance to those firms, a recurring topic of policy interest and one of the strategic themes of the 2004 action plan.

\subsection{Business sector}

The dataset reveals a marked contrast in the balance of business activity between deprived and non-deprived areas. Deprived areas have a significantly higher proportion of their business stock engaged retailing, manufacturing and hotels \& catering. Balancing this is a comparative absence of firms involved in construction and business services.

One possibility is that these differences reflect the concentration of deprived areas in particular regions of the country and thus wider geographic variations in business stocks. For clarity we examine only one dimension of this - the variation in the proportion of the business stock in the business services sector. Figure 2 presents these proportions split by both regional ${ }^{9}$ and deprived/non-deprived categories, with the national deprived and non-deprived averages for comparison.

The chart shows that there are variations in the share of deprived area business stocks accounted for by business services, from $18 \%$ in the West Midlands to $25 \%$ in London. However, the more important point shown by the data is that in all but one region - the East Midlands - the share of business services in deprived areas is significantly lower than in non-deprived areas. Even without controlling for other differences in the business and population profiles of regions, this result provides fairly strong support for the view that the type of business activity in deprived areas varies in a consistent way from that found elsewhere. 
Figure 2 Business services by region (see online version for colours)

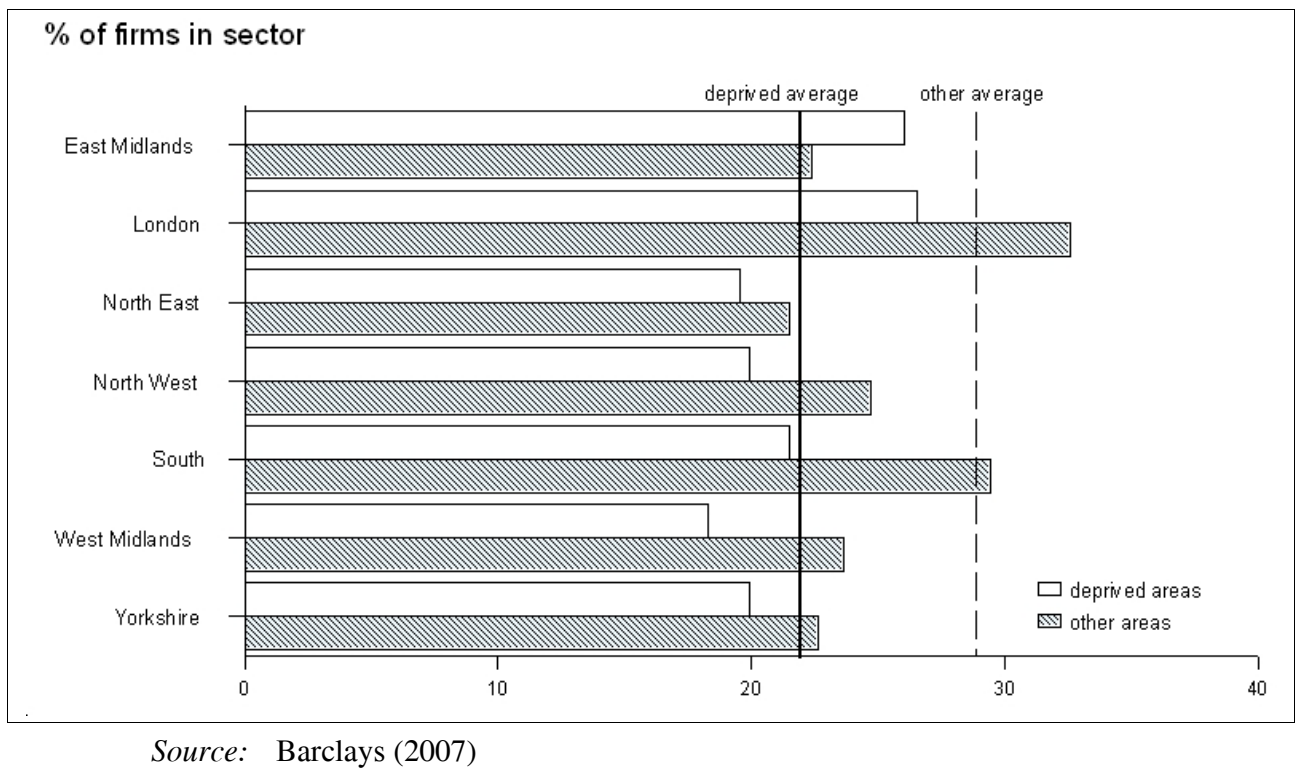

\subsection{Female involvement}

As noted above, female enterprise is a particular topic of policy concern at present. For the dataset female involvement is captured by looking at the gender of individuals recorded by Barclays as being associated with a given business as an owner, a director or a partner. On this definition the dataset (see Table 2) shows that there is a significantly lower level of female involvement - the proportion of businesses with at least one associated female - in deprived areas.

Could this 'gap' of three percentage points reflect a difference in the gender balance between deprived and non-deprived areas? It is very unlikely. Estimates by the UK Office for National Statistics show that, in fact, the balance is the other way, with a greater proportion of females in the population of working age in deprived areas. Is the difference the result of varying rates of female involvement across the regions? Figure 3 shows the rates of female involvement across the regions, again split into deprived and non-deprived areas.

As with the share of business services, the data show, with one exception, a clear pattern of lower female involvement in deprived areas. In all cases, bar one, participation is three to four percentage points lower. The exception is in the south of England, where the limited number of deprived areas may mean that they have less distinctive characteristics than in other regions of the country.

Given that the lower level of involvement does not appear to be related to variations in gender balance, either between deprived and non-deprived or between regions, what other reasons might lie behind the observed difference? The most likely factor is the socio-economic profile of deprived areas. For example, more limited resources could disproportionately restrict female enterprise. However, it is not possible to address this issue in more detail with the data available for this paper. 
Figure 3 Female involvement by region (see online version for colours)

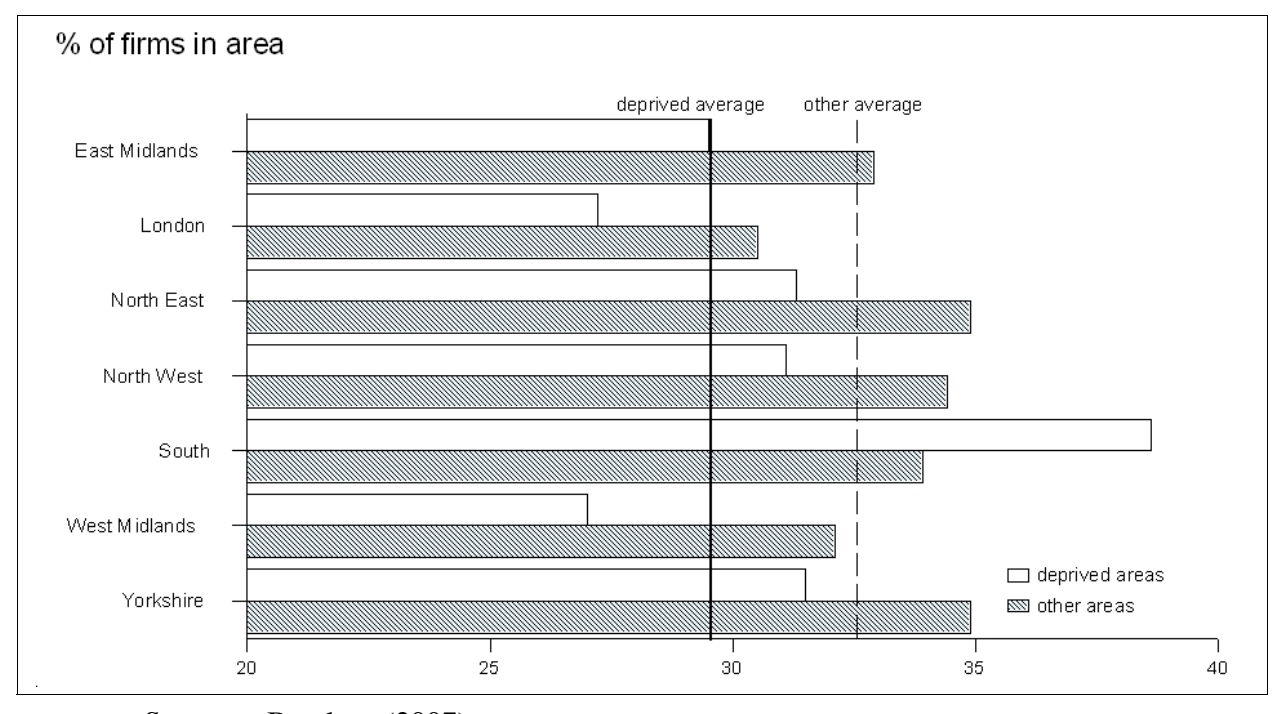

Source: Barclays (2007)

\subsection{Risk}

The ability of small firms to access external finance is of perennial interest to policymakers. For this analysis we are able to examine this issue from the perspective of the primary provider of external finance - their bank.

Barclays uses a behavioural scoring model, based on a range of observable activity measures, to assess the likelihood of default in the next 12 months. This score is generated for every business customer and revised every month, whether or not the customer is actually borrowing or has applied for finance. For the purpose of this paper we use the resulting scores to assess the relative risk profiles of business activity in deprived and non-deprived areas, although in practice they are only one aspect of the lending decision.

For this analysis each firm in the dataset is grouped into one of six risk categories covering the most risky $10 \%$ of customers, the next $10 \%$ of customers and then successive $20 \%$ bands. This allocation is based on the full distribution of scores, including businesses not in urban areas.

Table 2 shows that businesses in deprived areas have a significantly poorer risk profile than those elsewhere in urban areas. Twenty-eight percent were located among the $20 \%$ lowest score, compared with less than $22 \%$ for other firms in the dataset. This does not necessarily mean that a substantially lower proportion of firms would be able to obtain finance, but it is likely that those at the margin will face higher costs either through increased interest rates and/or greater collateral requirements. This is consistent with findings from research by the Bank of England (2000) that interest margins were higher among businesses in deprived areas.

In part this adverse risk distribution could reflect other business characteristics set out in Table 2, most notably the relative youth of the business stock in deprived areas. What is clear from the dataset is that the risk profile is, along with sector composition and female involvement, not simply a reflection of the geographic distribution of deprived 
areas. Figure 4 shows the proportion of firms in the bottom $20 \%$ of the risk distribution by region and area type. The data reveal that riskier firms are disproportionately located in deprived areas in each region. These differences are statistically significant, with the exception of the North East.

Figure 4 Risk profile by region (see online version for colours)

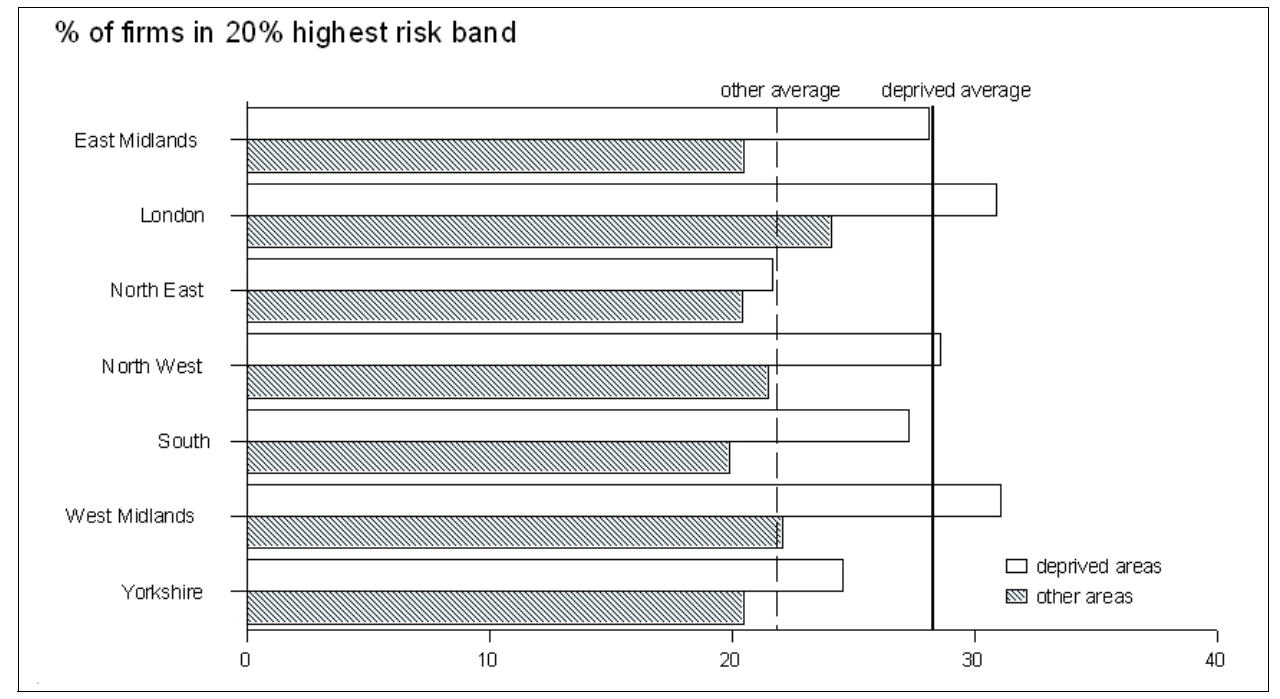

Source: Barclays (2007)

The relative risk profiles shown in Figure 4 raise an interesting question. We have seen that the North East is a region with a high proportion of sectors in deprived areas. However, the firms in these areas, exceptionally, do not appear to be riskier that the wider business stock in the region. Indeed, they are less risky than a typical group of firms drawn from non-deprived areas in general. This is a sharp contrast with London where the risk profile appears to be relatively poor across the board. These results appear to jar with perceptions of the relative economic performance of these regions. The answer may lie in differing volumes of businesses. Official data (SBS, 2006) shows that there are far more firms per person in London than the North East. This suggests that the 'additional' businesses in London are likely to be more 'marginal' than average, with a corresponding impact on the risk profile.

\section{Analysis: dynamics}

In the previous section we examined three aspects of the business stocks of deprived and non-deprived areas. However, to gain a clearer understanding of the business profile of areas it is necessary to take some account of the stock dynamics produced by entry, exit and growth. In this section we use a sample of 12000 start-up firms to compare experiences of business survival and growth in deprived and non-deprived areas. 


\subsection{Survival}

The sample of new firms from 2002-2003 contains 1100 start-ups from deprived areas and 10900 from other areas. Business survival rates are estimated by looking at the proportion of firms remaining on Barclays customer records a given period after start-up. This does not account for firms that may have switched bank provider or ceased to trade, but without closing their account(s). However, provided that the incidence of these occurrences is similar across the country this approach allows a comparison of relative survival rates between areas. ${ }^{10}$ Figure 5 shows the survival rate profiles for deprived and non-deprived areas in the four years after start-up.

Figure 5 Business survival rates, 2003-2007 (see online version for colours)

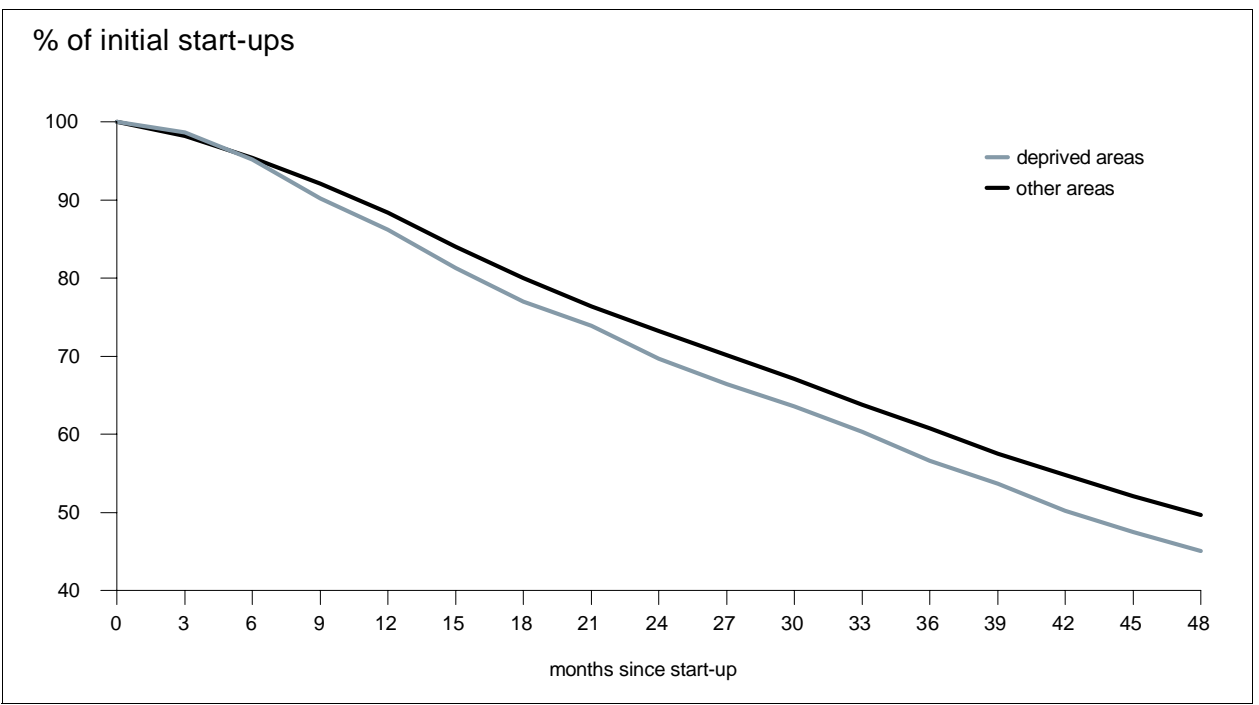

Source: Barclays (2007)

Although the data are not adjusted for sectoral composition, it does indicate a small, but appreciable difference in the survival rates between deprived and other areas. After four years $45.1 \%$ of new firms from deprived areas remained, against $49.7 \%$ in non-deprived areas. This higher attrition rate links back to the stock profiles in two main ways. First, it is consistent with the relative youth of businesses in deprived areas. Second, it is likely to have common causal factors with those that ultimately lie behind the relatively poor risk profile of those areas.

The limited sample size means that it is not possible to present this data on a regional basis. However, it is important to remember that, within reason, lower survival rates may not be an issue of specific concern. A low survival rate is consistent with a relatively high rate of entry into and exit from the business stock. This is the case in London, where implied low survival rates do not appear to have an undue negative impact on economic performance. 


\subsection{Growth}

Using the same sample of new firms it is possible to compare the growth performance of new firms. For this analysis our growth measure is debit turnover in the second, third and fourth year after start-up. As with the assessment of survival rates, these data do not account for firms that may have switched bank by a given point. Figure $6 a$ shows the proportion of start-ups recording debit turnover of at least $£ 50,000$ and $£ 250,000$ in the stated time periods. Figure $6 \mathrm{~b}$ shows the data scaled to the number of surviving, rather than start-up firms.

Figure 6a Business growth performance (see online version for colours)

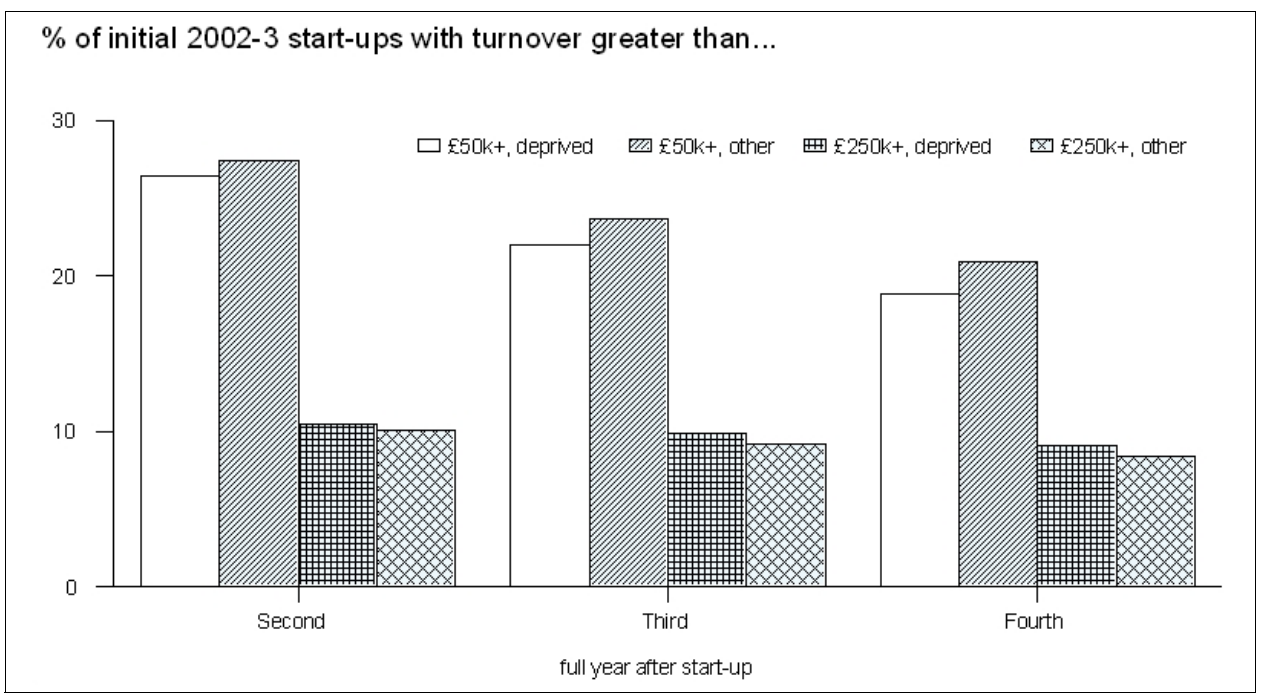

Source: Barclays (2007)

Figure 6b Business growth performance (see online version for colours)

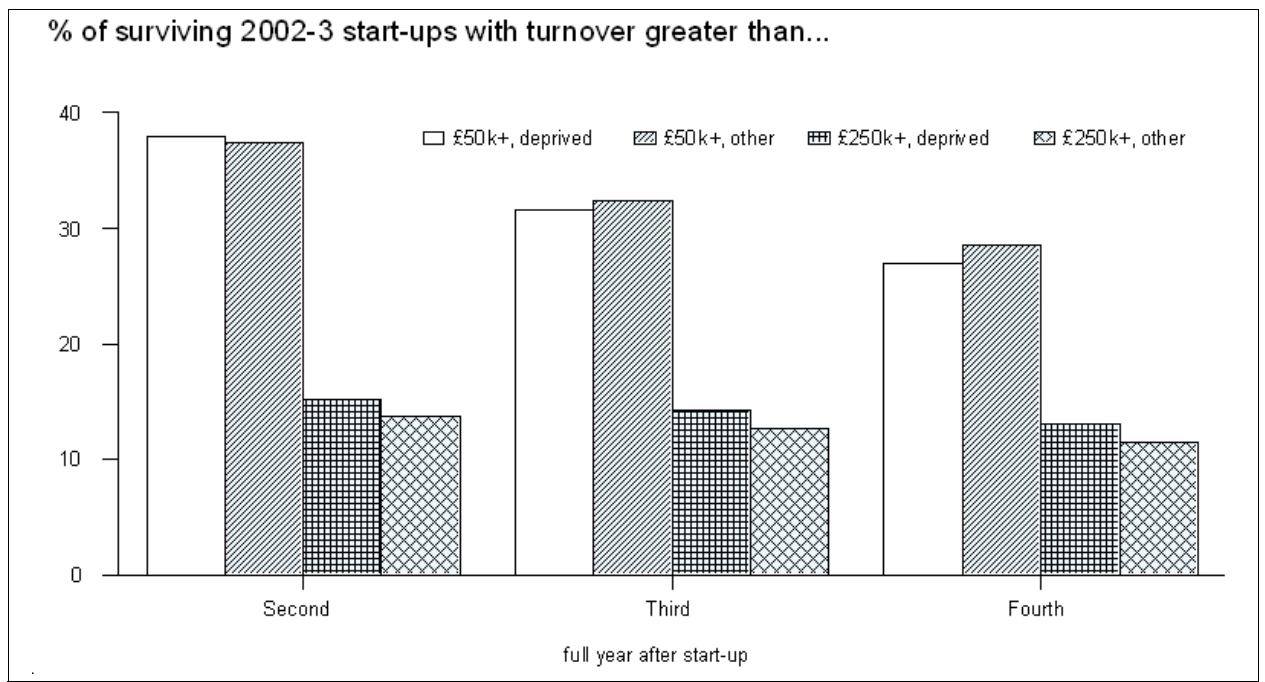

Source: Barclays (2007) 
The data indicate that the proportion of new firms reaching the two size thresholds does not differ substantially between deprived and non-deprived areas. Indeed, in the case of the larger threshold a slightly higher proportion of start-ups in deprived areas attained this mark during each time period $-9.1 \%$ in the fourth year against $8.4 \%$ elsewhere. This gap becomes larger when assessed relative to all firms surviving to that point.

The growth performance of start-ups in deprived areas is perhaps a little surprising given perceptions about the economic status of these areas. One possibility is that it is merely a result of the time period used for this analysis. Another interpretation might be that the results show that firms above, or growing to, a certain size become detached from their immediate economy. That is, with a turnover above $£ 250,000$ a firm is no longer dependent on demand from the local area. Indeed, some owner-managers from outside deprived areas may start-up in deprived areas to utilise the advantages they provide in terms of lower cost premises and labour. The data certainly suggest a sharper division within deprived area start-ups, with the chances of failing to survive and reaching a substantial size both higher than in other areas. It appears that 'modest' new firms are less resilient in deprived areas, perhaps due to the nature of local demand and/or the high rate of new entry noted earlier.

A final point is that this comparison of growth performance has looked at only the proportion of new firms reaching certain thresholds. It could be that if equivalent data were to be presented for the entire start-up population then the rate of new growth firms - relative to the local population - would turn out to be lower in deprived areas.

\section{Conclusion}

The starting point for this paper was the observation that a significant number of small business/enterprise policies now have, in contrast with most previous ones, an explicit deprived areas dimension. In the preceding sections we used a large dataset to provide an initial analysis of whether segmenting the business stock in this way provides additional value beyond other possible approaches to sub-dividing firms, e.g., by sector, size, etc.

Our initial analysis of the data available to us suggests that deprived areas of England vary systematically from the wider economy in many of their business stock characteristics and associated dynamics. Section 5 provided an overview of differences in the stock - including size, legal form and age - together with more detailed analyses of variations in sector composition, female involvement and risk, aspects of the stock we consider to be of particular policy interest. Section 6 examined contrasts in survival rates and growth performance. Taken together, these marked differences indicate that there could be benefits from the tailoring of policies to sub-national levels. In effect, these results broadly support the approach of national policy over the last decade in frequently treating deprived areas as a distinct group of locations that need special attention.

However the analysis does not necessarily imply that all deprived areas should have similar policies. Figures $2-4$, showing the differences between deprived and non-deprived areas, also made clear that the regional structure of deprived areas can also show marked variations. Again, in line with current public policy developments, this conclusion supports the view that if public policy to boost enterprise is seen as a desirable activity it should be customised to local circumstance (e.g., through a process such as a 
Regional Economic Strategy). It is for this reason that we intend to extend our analysis to a more detailed examination of deprived areas at a local level, to better understand how business activity varies between superficially similar areas.

A final point to make is that analyses of datasets such as the ones used in this paper can only move forward our understanding so far. It can confirm things we may have suspected, such as the risk profile of deprived areas, or surprise us, revealing the low level of female involvement. Even so, they are unable to account for why high risk factors are prevalent in these areas or conversely, why female engagement is apparently low. For that we need to draw on additional data sources.

A comparison can be made here between deprived areas and ethnic minority (EMB) policy research (BBA, 2002; WBS, 2005). In the case of EMB research, it is now accepted wisdom that variations between EMB groups are often more significant than between EMBs as a whole and the non-EMB population. The analysis presented here suggests this is just as likely to be the case for the issue of enterprise in deprived areas.

We believe this paper has made a start on highlighting the questions that need to be asked. However, to move towards a greater understanding of enterprise in deprived areas we will need to combine use of selected bank data in conjunction with enhanced official statistics, other commercial data and/or detailed locally sourced information. This points to further development of research methods, including drawing on the tradition of the detailed local case study approach to policy research and evaluation (e.g., Storey and Strange, 1993).

\section{References}

Bank of England (2000) Finance for Small Businesses in Deprived Communities, Bank of England, London.

Barclays (2007) Corporate Social Responsibility Report 2006, London: Barclays Bank.

BBA (2002) Ethnic Minority Business in the UK: Access to Finance and Business Report, London: British Bankers Association.

BBA (2007) BBA Abstract of Banking Statistics 2007, London: British Bankers Association.

BERR (2007) 'Small and Medium-Sized Enterprise (SME) statistics for the UK, 2006', Methodology and Accuracy; Technical Note, London: Department for Business, Enterprise and Regulatory Reform.

Co-op (2006) Sustainability Report 2005, Manchester: Co-operative Financial Services.

DTI (2007) 'Survival rates of VAT-registered enterprises, 1995-2004', Key Results, London: Department of Trade and Industry.

Frankish, J., Roberts, R. and Storey, D.J. (2006) 'Charting the valley of death - closure rates among new businesses', Paper for ISBE 29th National Conference, 30 October-1 November.

Gavron, R., Cowling, M., Holtham, G. and Westall, A. (1998) The Entrepreneurial Society, London: IPPR.

HM Treasury (1999) Enterprise and Social Exclusion, London: HM Treasury.

McGeehan, S., Forster, S. and Mayo, E. (2003) The Power of Information: Opportunities for Disclosure, London: New Economics Foundation.

ODPM (2004) The English Indices of Deprivation 2004: Summary (revised), London: Office of the Deputy Prime Minister.

ONS (2007) UK Business: Activity, Size and Location - 2007, London: Office for National Statistics. 
SBS (2004) 'A government action plan for small business', Small Business Service, London: Department for Trade and Industry.

SBS (2006) 'SME statistics for the UK 2005', Small Business Service, London: Department for Trade and Industry.

Storey, D.J. and Strange, A. (1993) 'Entrepreneurship in Cleveland 1979-1989: a study of the effect of the enterprise culture', Employment Department Research Series No. 3, London: Department of Employment.

Thomas, W., Brown, J., Bush, M. and Smith, G. (2006) Full Disclosure: Why Bank Transparency Matters, London: New Economics Foundation.

WBS (2005) Finance for Small and Medium-Sized Enterprises: Comparisons of Ethnic Minority and White Owned Businesses, Coventry: Warwick Business School.

Westall, A., Ramsden, P. and Foley, J. (2000) Micro Entrepreneurs: Creating Enterprising Communities, London: IPPR.

\section{Notes}

1 While more small business measures were introduced during this period, these were part of a national, rather than sub-national, framework.

2 There are equivalent indices for Scotland, Wales and Northern Ireland. However, differing methods of construction mean that the four indices are not readily compatible.

3 These are geographic areas defined by the UK Office for National Statistics (ONS) based on the 2001 UK Census. They contained an average of 1500 individuals and, unlike other geographic units, will remain fixed until the 2011 Census is available.

4 Based on the ONS classification of local areas contained in the NSPD.

5 This reduces the number of deprived sectors to 772 .

6 See McGeehan et al. (2003) for a study using bank data in a limited number of areas.

7 See http://www.bba.org.uk for aggregate data.

8 The data presented in this paper does not adjust for variations in Barclays market share across England. However, comparison with a dataset weighted to adjust for this factor does not indicate any changes that would alter the current analysis.

9 The three regions - East of England, South East and South West - are presented as a single 'South' composite region. This reflects the relatively small number of sample firms in deprived areas in each of these regions.

10 See Frankish et al. (2006) for a comparison of Barclays account and customer based survival rate estimates and those provided by analysing VAT registered firms (DTI, 2007). In addition, switching rates are modest - c.4\% a year - and most small firms use only one bank. 